\title{
La Nicaragua posible: Los cambios necesarios
}

Recibido: 05 de octubre de 2012/ Aprobado 10 de octubre de 2012.

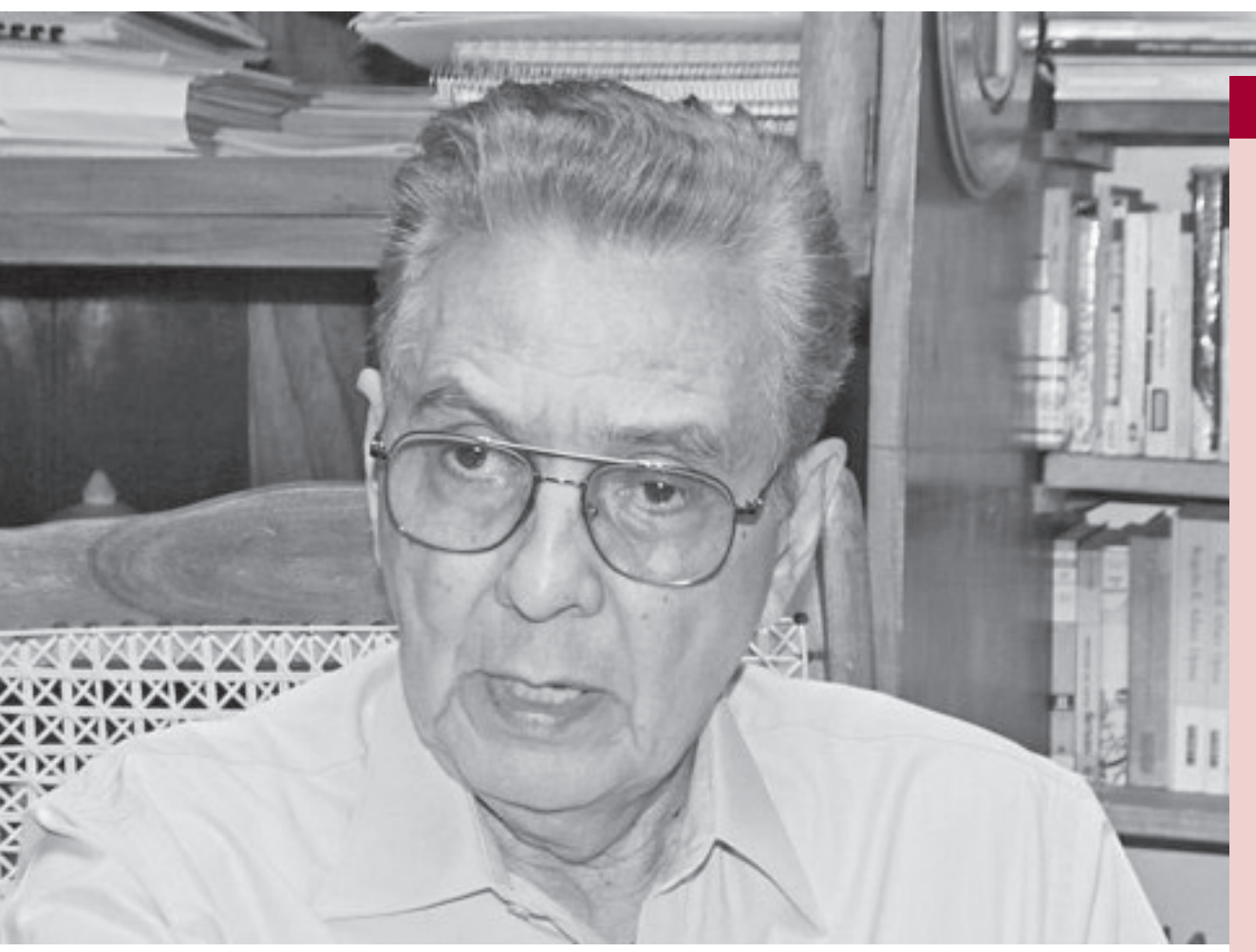

\section{RESUMEN}

Alejandro Serrano Caldera ${ }^{1}$

elnuevodiario.com.ni

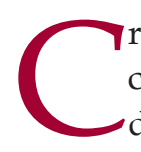

Yreo que los nicaragüenses nos encontramos en un cruce de caminos, en una encrucijada y por lo tanto tenemos que decidir y decidir bien. Estamos también ante la oportunidad de recapitular y enmendar nuestras fallas y restaurar nuestras fracturas históricas.

La situación actual de Nicaragua es de fragmentación, debilitamiento de valores y ausencia de objetivos comunes, a tal grado que se obscurece el futuro inmediato por la sombra de los fantasmas del pasado que habitan el presente. Al lado de la fragmentación general se produce la concentración del poder en manos de quien ejerce el gobierno y el liderazgo político de su partido. Una cosa no excluye la otra; al contrario, la concentración de poder es consecuencia de la fragmentación en las diferentes esferas políticas y sociales, las que, en esas condiciones, están imposibilitadas de impedir la configuración del autoritarismo del poder personal.

1 Filósofo y politólogo nicaragüense.
El pensador Alejandro Serrano, aborda los cambios sustantivos que Nicaragua necesita para superar la realidad actual, caracterizada por la fragmentación y la concentración del poder, factores que han determinado las crisis cíclicas de una historia ensangrentada de nuestro país. Plantea la concertación como un proceso participativo, en torno a 3 ejes: política institucional, económico-social y educativo, en función de avanzar a un plan de país, base para un cambio en nuestra cultura política.

Palabras clave: fragmentación, concentración de poder, teoría, práctica, proyecto de nación.

\section{ABSTRACT}

Ever thoughtful, Alejandro Serrano addresses the significant changes needed in Nicaragua to improve the current reality, which is characterized by fragmentation and power-grabbing. These factors have caused a cycle of crises throughout the bloody history of our country. He puts forward the ideals of political compromise as a participatory process with three areas of focus: institutional policies, socioeconomic factors, and education. The ultimate goal is to enact a plan for the country based on a change in our political culture.

Key words: fragmentation, powergrabbing, theory, practice, national project 
Fragmentación por un lado y concentración por el otro configuran el mapa de la disímil situación nicaragüense, cuya contradicción estructural no es un signo de estabilidad y desarrollo, sino más bien de incertidumbre y de posible crisis.

Cuando una situación presenta las características que en términos generales estamos tratando de describir, nos encontramos en una "sociedad disociada" cuyo peligro de colapso afectaría no sólo a los sectores políticos y sociales fragmentados y parapetados en sus compartimientos estancos, sino a la sociedad en su conjunto. Por ello, y viendo más allá de ideologías, partidos, personas, o grupos diversos, pensamos que es imprescindible la creación de un verdadero movimiento político y social, capaz de enfrentar las acciones que lesionen la democracia, el Estado de Derecho y el sistema institucional, y que, contribuyan a sentar las bases de un régimen autoritario o, peor aún, de una dictadura. Se trata de construir un movimiento que formule e impulse un proyecto de nación y un plan estratégico de desarrollo político, económico, social e institucional.

Para ello habría que dar una serie de pasos entre los que podrían mencionarse, el acuerdo entre los partidos para construir la unidad; la concertación y acuerdo entre estos grupos y las organizaciones de la sociedad civil para estructurar una propuesta conjunta; la realización de un proceso de discusión y acuerdo a nivel nacional, regional, departamental, local, sectorial, de la propuesta o proyecto estratégico; la definición de los contenidos puntuales de los aspectos principales del proyecto el que, a nuestro juicio, debería priorizar como ejes fundamentales, los aspectos político-institucional, económico-social y educativo. Una vez culminado el proceso de discusión, y con los aportes reunidos en el mismo, debería elaborarse el documento integral y presentarse a la nación el plan de país.

Creo, sin perjuicio de lo que se considere más adecuado, que deben asumirse un conjunto de valores y establecerse los fines del proyecto, entre los cuales, valores y fines, podrían mencionarse, libertad, legalidad y legitimidad, es decir la coincidencia de la ley con la expresión de la voluntad general; subordinación del poder a la ley; política social como contenido, sentido y dirección de la política económica; y construcción de ciudadanía, base de una verdadera democracia.

Es el momento, a través de una concertación sistemática, integral y con visión de futuro, de dotarnos de una identidad política y jurídica de la que hemos carecido. Esto sólo será posible si hacemos de lo político un acuerdo fundamental y de lo jurídico un cuerpo normativo que responda plenamente a nuestra realidad histórica y que sea a la vez expresión de esa realidad, cauce por el que discurra nuestra vida política y social e instrumento que contribuya a reproducirla en todas expresiones.

Esto nos permitirá por primera vez integrar un sistema y un modelo político a la realidad e integrar los enunciados jurídicos a la práctica, superando lo que Carlos Fuentes ha llamado "La separación esquizoide del derecho y la práctica". ${ }^{2}$

Es la oportunidad de definir un modelo económico viable y una política económica unitaria mediante un acuerdo socio-económico entre el gobierno, los empresarios y los trabajadores que permita consolidar los derechos fundamentales de los trabajadores de la ciudad y el campo, y el derecho al salario, y al empleo. Que permita también garantizar, junto al derecho al trabajo, la eficacia productiva, todo ello dentro de políticas globales, con objetivos, metas y estrategias perfectamente identificables y coherentes.

Sobre la base de la definición de los contenidos políticos, jurídicos y económicos, habría que proceder a redefinir el Estado, su estructura y su papel y a posibilitar que la sociedad civil, por sí misma, se desarrolle y fortalezca.

Esto implica superar definitivamente el concepto y práctica del poder vertical, clientelista y personal, por otro, horizontal, solidario y participativo.

Repito, creo que es este el momento de dar un contenido concreto a la concertación, superar la ambigüedad por el rigor y claridad conceptual y práctica, y tratar de alcanzar a través de ella y del acuerdo social a que conduzca, no sólo la solución de los problemas puntuales, sino también de los grandes problemas históricos, como la falta de identidad política, que ha impedido nuestro desarrollo

2 Carlos Fuentes. Tiempo Mexicano. Ed. Joaquín Mortiz S. A. Pág. 127, México. DF. 1980 
y ha hecho de la violencia un estilo y una norma de conducta.

El problema de la identidad política del nicaragüense está estrechamente ligado al problema de la legitimidad del poder.

Para la cultura política de nuestro país no existe, o existe muy débilmente, el sentido de institución. Quizás la poca consistencia institucional de nuestra forma de organización política precolombina, sumada a la prevalencia de ese espíritu autocrático y militar cuya práctica se acentúa con el colonizador español, impidió que el poder se transformara en institución. Más bien el cacicazgo devino caudillismo en la práctica política de los Estados Nacionales surgidos de la Independencia.

En este sentido,la institución no existe como tal; existe sólo como mecanismo externo, como instrumento para facilitar el ejercicio del poder, para manipular, para justificar. La historia de Nicaragua ha sido de escepticismo acerca del principio de legalidad. Salvo excepciones que confirman la regla general, se puede decir que nadie, ni gobernantes ni gobernados, han creído en el principio de legalidad. En el mejor de los casos lo han utilizado para maquillar y dar cierta apariencia a las decisiones y acciones de facto.

Se ha creído en la fuerza, con maquillaje o sin él, pero no en el derecho (sobre todo en el Derecho Constitucional) porque éste le ha sido ajeno.

Pero el problema es todavía más profundo pues no sólo no se ha fundado nuestra legitimidad política en el principio de legalidad, sino que usamos éste como si creyésemos en él y construimos a su alrededor un discurso de legitimación del derecho y de la institucionalidad, en el cual no creen ni quien lo dice, ni sus partidarios, ni sus adversarios.

Se genera así una nueva esquizofrenia causa de la fractura y separación de dos universos: el universo de la práctica y el universo del discurso.

La otra expresión esquizofrénica es la fractura entre el enunciado jurídico y la realidad política, económica y social.
Se crea así una especie de reglas implícitas, una suerte de "ética" política tácita en las que el discurso no sirve para expresar sino para encubrir.

En el fondo permanece como precipitado de nuestro actuar la idea de que es la fuerza la verdad de la historia, su razón de ser, cualesquiera sean las formas o reformas, los textos o pretextos con que se la quiera recubrir.

Hay, en lo más profundo de nuestro ser individual y colectivo una especie de conciencia soterrada, silenciosa y crepuscular sobre la realidad absoluta de la fuerza, cuando no una conciencia lúcida de la conveniencia política de la doble moral entre el discurso y la práctica.

Con tal fragilidad institucional y tal tradición autocrática y factual integrada ya a la ontología del nicaragüense, es imposible esperar que sin un cambio de nuestros valores que cambie también nuestras actitudes y conductas, podamos salir del círculo de la violencia recurrente. Es necesario fundar la acción histórica sobre una verdadera ética política.

Creo que este momento es clave para lograrlo, a condición de que todos asumamos a fondo y sin subterfugios nuestra realidad. La concertación y el acuerdo social constituyen esa posibilidad siempre y cuando los

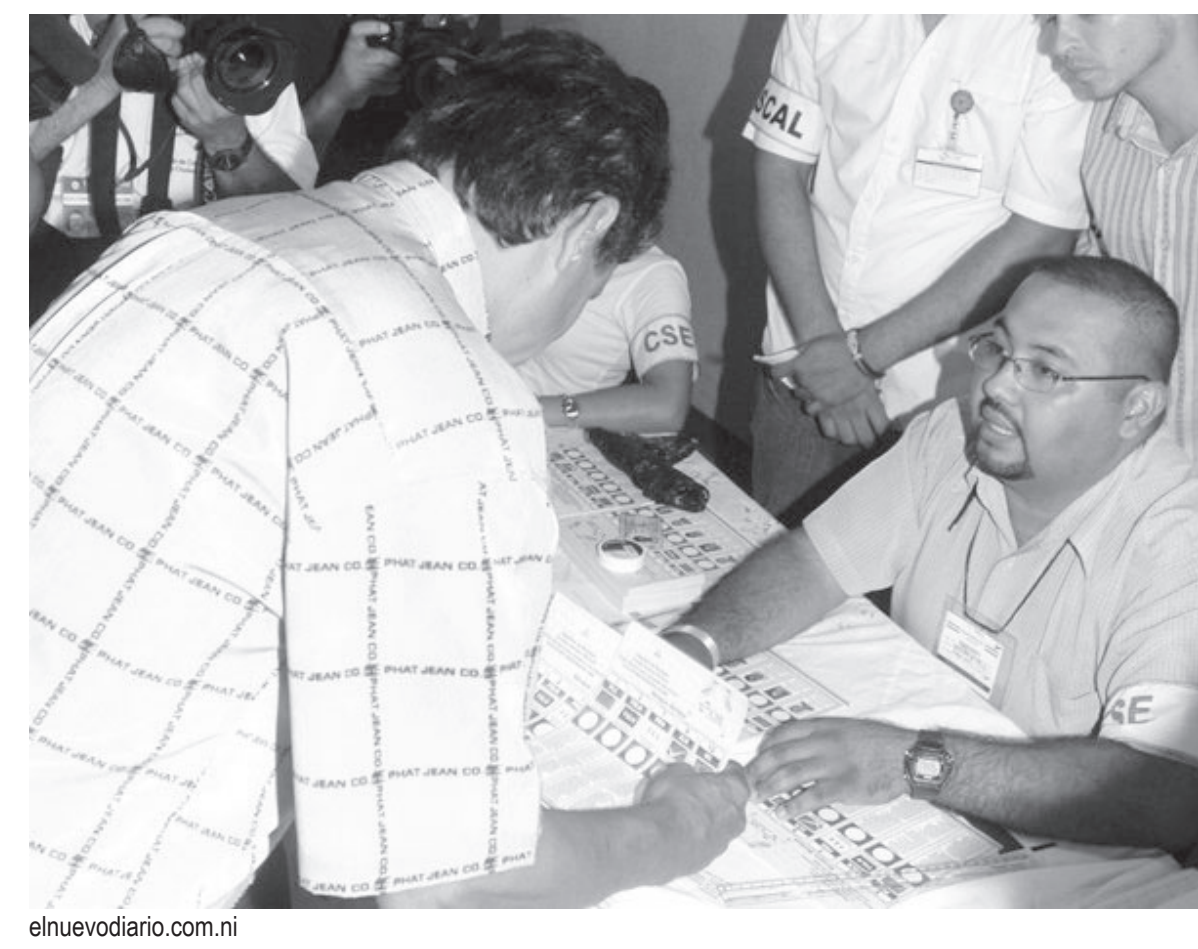


entendamos correctamente. Esto significa que el acuerdo social que surja de la concertación debe ser un auténtico proyecto de nación, cuya expresión más inmediata debe ser un plan o estrategia de desarrollo nacional.

El vacío fundamental que padece nuestra vida política es la ausencia de ese plan nacional de desarrollo, de esa propuesta construida entre todos de lo que debe ser nuestro proyecto de nación.

Insisto, hay que esforzarse porque la concertación sea la estructuración de la verdadera estrategia de desarrollo nacional y de la formulación del auténtico proyecto de la nación nicaragüense.

Los acuerdos coyunturales sin una estrategia nacional, sólo diferirían nuestros problemas sin resolverlos. Serían logros pírricos y momentáneos cuando de lo que se trata es de asumir a fondo nuestra historia y nuestro futuro.

Se trata de entender la concertación como la oportunidad y el momento de elaborar nuestro proyecto de nación. Para ello tenemos que superar los aspectos más negativos de nuestro ser, identificar con honestidad nuestras debilidades y asumir con entereza la decisión de enfrentarlas.

Junto a las mejores cualidades del nicaragüense, generosidad, valentía y solidaridad, anidan otras en forma germinal o en desarrollo que no sólo debilitan y enturbian la fuerza y transparencia de las primeras, sino que dificultan la consolidación de nuestra identidad histórica.

Algunas actitudes negativas parecieran constituir una tendencia mayoritaria entre nosotros los nicaragüenses. La negativa a reconocer nuestras limitaciones, las que encubrimos y falsificamos, la poca conciencia sobre el valor histórico de las instituciones, la fascinación por la fuerza y la conducta de facto, la aceptación de la normalidad de la fractura entre el discurso y la práctica política, que nos sitúa en la contradicción permanente en un discurso que dice lo contrario de lo que se piensa y de lo que se hace. Negativa a reflexionar y dialogar sobre esas limitaciones propias, sino de todos al menos de un sector importante de la comunidad nacional, porque antes que nada nos negamos a reconocerlas en nosotros mismos pues rechazamos a reconocernos mediante la introspección.
Incapacidad de diálogo, pues no dialogamos, sino que descalificamos a nuestro interlocutor, no argumentamos sino que demolemos a nuestro adversario mediante el chiste mordaz y la carcajada.

Difícilmente en nuestros debates soportamos la argumentación y la exposición reflexiva.

Conversamos sobre la base de afirmaciones categóricas, juicios definitivos, frases herméticas, conceptos absolutos e inapelables que se aceptan o se rechazan, se toman o se dejan.

En el diálogo como en la práctica política sólo admitimos la sumisión o la guerra, generalmente encubrimos nuestra incapacidad dialógica con el argumento, (que es un autoengaño), que para nosotros no existen los términos medios.

Apreciamos, más de lo debido, la palabra fácil, la respuesta rápida como un rayo, el doble (y triple) sentido, el juicio mordaz. Esto nos dificulta el diálogo pues para nosotros resulta más fácil demoler que convencer, o, peor aún, que ser convencidos.

Con tales características no es de extrañar que nuestras reacciones de rapidez felina tengan por objetivo la violencia o el acomodo, el facto o el pacto, que transpuestas al escenario de la historia y la política entretejen el diseño de nuestra dramática realidad y nos aprisiona en una red de conductas ambiguas de la cual es difícil salir, la falta de identidad política de alguna manera refleja nuestra falta de identidad. Hay que hacer un esfuerzo por superarla y buscar una actitud más auténtica y genuina. Creo que esto es posible en las nuevas generaciones, en los jóvenes que son el presente y el futuro de Nicaragua.

No pretendo con esto dar a un proceso de concertación política más valor que el que efectivamente tiene, ni mucho menos suponer o hacer creer que de un acuerdo social brotará como por encanto la identidad del nicaragüense. Claro que no; la concertación no es la piedra filosofal, ni vamos a restituir en unos cuantos meses de diálogo como por arte de magia las fracturas estructurales de la historia, ni los vacíos esenciales del ser nicaragüense.

La concertación es un proceso político y como tal debemos valorarla. Pero es un proceso político que toca problemas 
cuyas raíces se encuentran sumergidas en la historia y en el subsuelo de nuestro ser individual y colectivo. Por ello debemos hacer un esfuerzo para que el tratamiento de todo problema puntual, sea hecho en forma integral y teniendo presente su nexo indisoluble con causas más profundas y radicales en nuestra historia.

¿Será posible establecer el equilibrio político? ¿Podrá desarrollarse el proceso de concertación y alcanzar un acuerdo social que siente los criterios fundamentales del quehacer político, económico y social de Nicaragua?

Creo que es imprescindible y urgente buscar soluciones nacionales que respondan a los más sentidos intereses del pueblo nicaragüense y que den respuesta las apremiantes preguntas que no sin angustia se plantea el país entero.

Esto exige, en consecuencia, precisar una serie de aspectos, entre otros los siguientes:

1. La concertación debe entenderse como un proceso sistemático y global, cuyo propósito esencial es llegar a configurar un acuerdo social, un proyecto de país. Debe también entendérsela como una forma de conducta política y un estilo de la democracia moderna de conducir la política y lo político, y, a la vez, como un instrumento preciso para dar respuesta perentoria a los problemas apremiantes que gravitan con dramatismo sobre nuestro pueblo.

2. El acuerdo o contrato social es el resultado de la concertación y debe establecer las obligaciones y los derechos específicos de todas las partes y el compromiso de su riguroso cumplimiento.

Esta conceptualización debería dejar claro, entre otras cosas, que la concertación, no es un acto esporádico y aislado, y que el Acuerdo o Pacto Social que de ella resulta, por ser, precisamente, un proyecto nacional, no puede confundirse con los clásicos pactos políticos que conocemos a través de nuestra historia y que tienen como propósito la repartición del poder entre las fuerzas políticas.

Si pasamos al sentido que la concertación asumeen nuestro país, habría que preguntarse ¿concertar para qué y para quién? y aquí es importante en la respuesta que se dé ser claro, riguroso y honesto. Para serlo más, comencemos por ver lo que la concertación no es o no debe ser. La concertación, no es, no puede ser, ni un instrumento para legitimar posiciones unilaterales preconcebidas, ni un medio para ganar tiempo postergando los problemas.

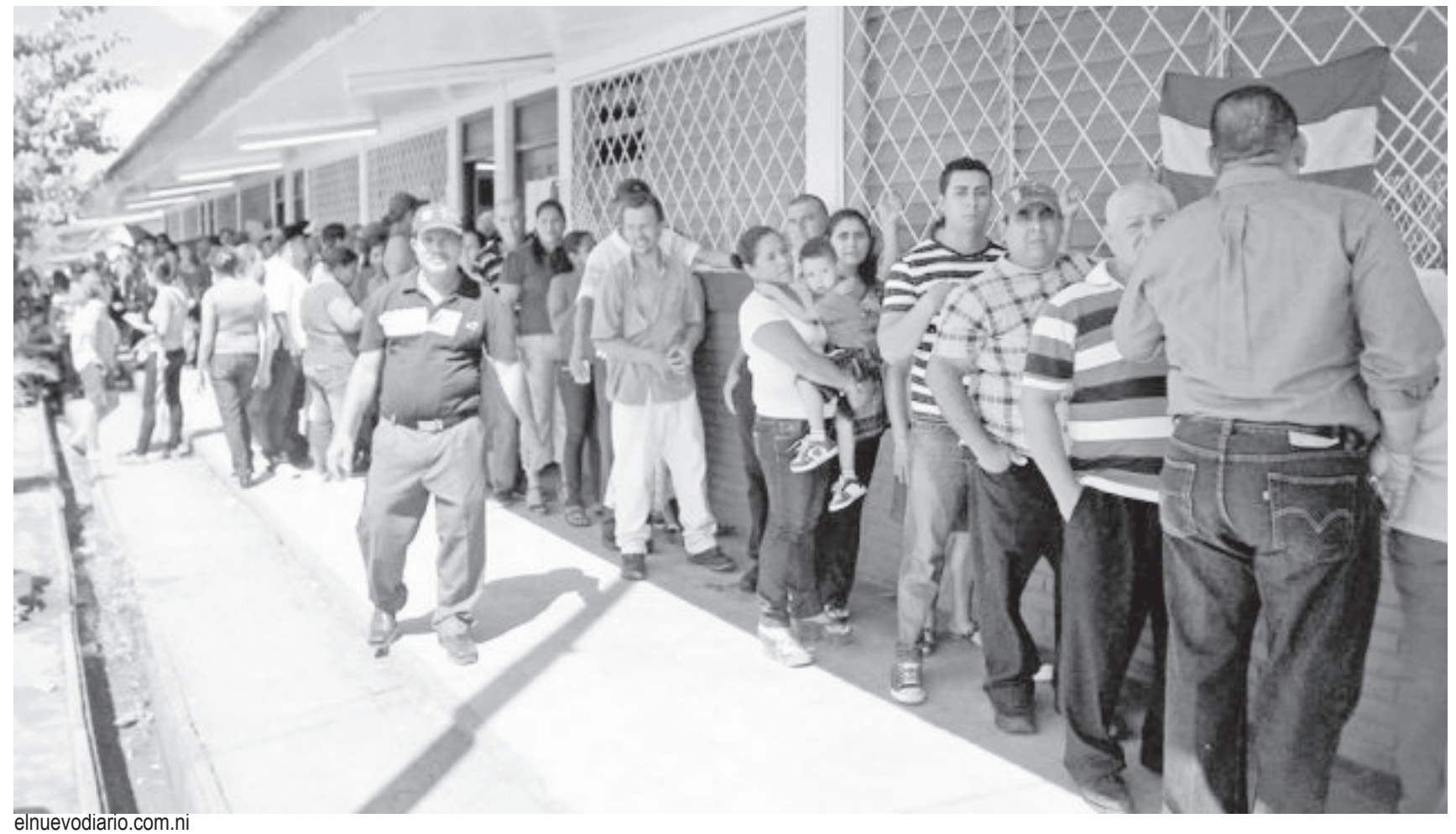


No es, entonces, ni imposición, ni claudicación, ni evasión. Es compromiso que obliga a todas las partes a su cumplimiento. El proceso para llegar a un acuerdo, a un pacto social equilibrado y justo.

En ese orden de ideas, y para ser coherente, debe llegarse a la conclusión que si bien la concertación es ya en sí misma un principio de acercamiento y distensión cuya importancia no se debe desconocer, tal principio no basta para alcanzar los objetivos que se persiguen. Podríamos decir que es necesario pero no suficiente. Para que sea suficiente es menester que se alcancen acuerdos reales sobre problemas esenciales. De lo contrario los problemas tendrán una solución temporal y las crisis serán recurrentes.

En ese marco conceptual, pensamos que en Nicaragua la concertación podrá ser efectiva si a través de ella se llega a un consenso sobre los principales problemas políticos, económicos y sociales y se cumplen, además, rigurosamente los compromisos.

Pero además, y ya en el plano más directamente político, jurídico e institucional, se torna imprescindible alcanzar acuerdos que nos conduzcan a la modernización del país, al fortalecimiento de la democracia (representativa y participativa) y a la consolidación del Estado de Derecho, mediante la subordinación a la ley de todo poder, cualquiera que éste sea.

Esto conlleva la reafirmación de valores fundamentales como el de la institucionalidad, modernización del Estado, fortalecimiento de la sociedad civil, alternabilidad en el poder, predominio de la civilidad; en fin, al desarrollo de una verdadera cultura política a la vez firme, tolerante y dialógica que nos permita superar el maniqueísmo y la polarización ideológica y política que es consecuencia, entre otras cosas, de la ausencia de una verdadera tradición civilista.
Realizar este cambio cualitativo sería una contribución para que el país adquiera una dimensión más coherente y realista al aproximar dos universos separados y contrapuestos: el país legal y el país real. Creo que esta acotación que hace Octavio $\mathrm{Paz}^{2}$ para la situación mexicana, es perfectamente válida para la situación nicaragüense.

Esa dicotomía consiste en tener por un lado, el país legal, país moderno enunciado en los textos constitucionales y en la legislación y el país real, pre-moderno, y con una práctica confrontativa y polarizada.

Bajo esa óptica entendemos el proceso de concertación: como un esfuerzo consciente de todos los nicaragüenses para diseñar y construir nuestro país. Esa visión de futuro y ese esfuerzo conjunto y solidario para alcanzarlo es lo que hemos llamado: La Nicaragua Posible. Tierra habitable y deseable que todos y cada uno de nosotros podemos construir cediendo un poco de lo que constituye nuestro objetivo político o el paradigma de nuestro modelo integral de sociedad.

La finalidad de la concertación es la construcción de la democracia. Pienso que la democracia es un sistema en el que deben considerarse la voluntad popular como su fuente originaria, el sistema legal e institucional como la forma necesaria que asume esa voluntad colectiva inicial, y el sistema de valores y principios como la base de todo sistema legal y político. Se trataría de esta manera de evitar el totalitarismo populista que puede llegar a adquirir ribetes trágicos, como nos lo han enseñado capítulos desgarradores de la historia de la humanidad, $\mathrm{y}$ el formalismo que puede llegar a anquilosar el verdadero sentido y la práctica de la democracia. Por ello, convendría interrogarse si principios como las garantías fundamentales de la persona y el ciudadano, la limitación al poder para evitar el absolutismo y la dictadura, el control recíproco de los poderes del estado,

2 Octavio Paz. Tiempo Nublado. Seix Barral. Barcelona, 1993. Pág. 165 
la subordinación del poder a la ley, siguen siendo, como yo lo creo, objetivos fundamentales de la democracia y de la búsqueda de la justicia, la estabilidad y la paz.

En todo caso considero imprescindible el esfuerzo colectivo para tratar de sacar al país del estancamiento en que se encuentra en su realidad política. No se trata sólo del cambio de cúpulas o de personas, sino de la necesaria transformación del sistema actual de oportunismos, prebendas, caudillismo, providencialismo, culto a la personalidad, violación a la Constitución, por otro caracterizado por el respeto a la Constitución, la subordinación del poder a la ley, la independencia de poderes, la participación ciudadana, la justicia social, el empeño por el desarrollo de políticas sociales en educación, salud, empleo, la renovación de los liderazgos, la participación de la juventud, entre otros objetivos a alcanzar, plenamente conscientes de que esta es una labor difícil que requiere tiempo, decisión y sacrificio, pero con la plena convicción que solamente con un cambio cualitativo e integral en el quehacer político, se puede salir del círculo vicioso en el que el país está atrapado, obligado a repetir una historia en la que el futuro es el pasado que regresa.

Algunos podrán decir que esto es una utopía, y que utopía es el lugar que no existe. Podría ser, pero en todo caso conviene recordar que si no existe es porque no ha sido construido todavía.

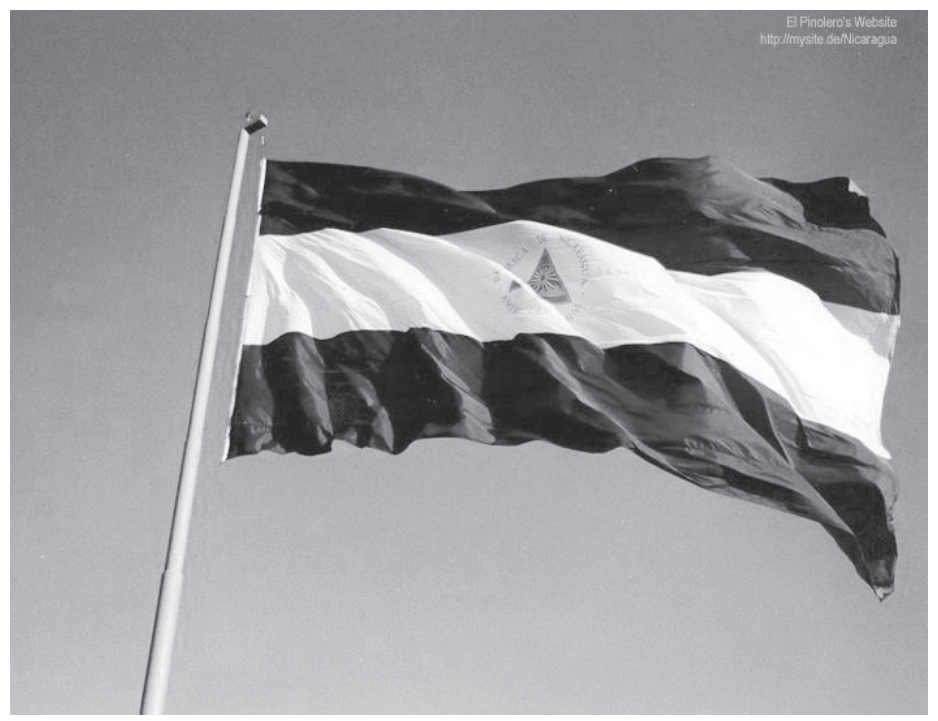

mapich.blogspot.com

\section{BIBLIOGRAFIA}

Carlos Fuentes: Tiempo Mexicano. Ed. Joaquín Mortiz S. A. México. DF. 1980

----- Valiente Mundo Nuevo. Fondo de Cultura Económica. México, DF. México. 1990

Octavio Paz: Tiempo Nublado. Seix Barral. Barcelona. 1993

Montesquieu: Del Espíritu de las Leyes. Editorial Claridad. Buenos Aires, Argentina. 1971

Locke: Ensayo sobre el Gobierno Civil. Editorial Aguilar. Madrid, España.1973

J.J.Rousseau: Contrato Social.Espasa-Calpe S.A. Madrid, España

Discurso sobre el origen de la desigualdad entre los hombres. Editorial Aguilar. Buenos Aires, Argentina. 1960

Giovanni Sartori: Aspectos de la Democracia. Editorial Limusa-Wiley S.A. México, D.F. 1965

Maurice Duverger: Introducción a la Política. Editorial Ariel S.A. Barcelona, España

Alejandro Serrano Caldera Los Dilemas de la Democracia. Segunda edición. Editorial HISPAMER. Managua, Nicaragua. 1998

Razón, Derecho y Poder. Reflexiones sobre la democracia y la política.Editorial HISPAMER. Managua, Nicaragua. 2004

Hacia un Proyecto de Nación. Fondo Editorial CIRA. Managua, Nicaragua 